\title{
PROFIL KONDISI FISIK: KECEPATAN, DAYA TAHAN, KELINCAHAN, DAN DAYA LEDAK SISWA SEKOLAH SEPAKBOLA KELOMPOK 15 TAHUN TINGKAT ELIT DAN NON ELIT DI PROVINSI DAERAH ISTIMEWA YOGYAKARTA
}

\author{
Sulistiyono \\ Ilmu Keolahragaan, Fakultas Ilmu Keolahragaan, Universitas Negeri Yogyakarta \\ Jl. Colombo No. 1, Karangmalang, Depok, Sleman, Daerah Istimewa Yogyakarta, Indonesia \\ sulistiyono@uny.ac.id
}

\begin{abstract}
Abstrak
Penelitian ini bertujuan untuk mengetahui profil kondisi fisik khususnya komponen kecepatan, daya tahan, kelincahan, dan daya ledak siswa sekolah sepakbola (SSB) kelompok umur 15 tahun tingkat elit dan non-elit di Provinsi Daerah Istimewa Yogyakarta. Metode yang digunakan adalah survey dengan sampel masing-masing berjumlah 30 siswa pada kelompok elit dan non elit. Komponen kondisi fisik siswa SSB kelompok umur 15 tahun tingkat elit memiliki profil kecepatan rata-rata 6,91 detik, daya tahan rata-rata 3,99 menit, kelincahan rata-rata 18,33 , dan daya ledak rata-rata $52,80 \mathrm{~cm}$, sedangkan tingkat non-elit memiliki profil kecepatan rata-rata 8,28 detik, daya tahan rata-rata 5,22 menit, kelincahan rata-rata 19,46, dan daya ledak rata-rata $48 \mathrm{~cm}$ dengan alat ukur kecepatan tes lari $50 \mathrm{~m}$, daya tahan tes lari $1000 \mathrm{~m}$, kelicahan dengan shuttle run test, dan daya ledak otot tungkai dengan tes vertical jump.
\end{abstract}

Kata Kunci: kecepatan, daya tahan, kelincahan, daya ledak, sekolah sepak bola

\section{PROFILE OF PHYSICAL CONDITION: SPEED, ENDURANCE, AGILITY, AND EXPLOSIVE POWER OF 15 YEARS OLD FOOTBALL SCHOOL STUDENTS (SSB) OF ELITE AND NON- ELITE LEVEL IN YOGYAKARTA SPECIAL REGION PROVINCE}

\begin{abstract}
This research intends to investigate the profile of the physical condition of speed, endurance, agility, and explosive power of 15 years old Football School (SSB) students of elite and non-elite level in Special Region of Yogyakarta Province. The method used was by survey where each sample consisted of 30 students at the elite and non-elite group. The physical condition components of 15 year age SSB students of elite level has average speed 6.91 seconds measured by $50 \mathrm{~m}$ sprint, aerobic endurance average $48.7 \mathrm{cc} / \mathrm{kg} /$ minute, agility average 18.33 measured by shuttle run, and leg muscle explosive power average $52.80 \mathrm{~cm}$, while the non-elite level has speed profile average 8.28 seconds, durability average 39.43, agility average 19,46, and explosive power average $48 \mathrm{~cm}$ with $50 \mathrm{~m}$ run speed measurement test, aerobic endurance, agility by shuttle run test, and leg muscle explosive power by vertical jump test.
\end{abstract}

Keywords: speed, endurance, agility, explosive power, Football School

\section{PENDAHULUAN}

Kompetisi sepakbola yang dikelola oleh FIFA dengan organisasi kepanjangannya ditingkat benua, sub-benua, sampai dengan negara terus berkembang. Piala Dunia (World Cup) adalah kompetisi sepakbola paling bergengsi yang dikelola FIFA. Piala Dunia diselenggarakan tiap empat tahun sekali sejak tahun 1904. Piala Dunia diselengarakan terakhir kali di Brasil tahun 2014 dimana Jerman berhasil merebut tropi Piala Dunia untuk ke-5 sejak diselenggarakannnya event Piala Dunia. Bagaimana posisi Indonesia di Piala Dunia? Indonesia sebagai sebuah negara 
tercatat belum pernah berpartisipasi di putaran final Piala Dunia. Indonesia sejak merdeka tahun 1945 sampai tulisan ini ditulis dalam keikutsertaannya pada event piala dunia maksimal sampai babak penyisihan grup zona Asia. Tim nasional sepakbola Indonesia belum mampu menunjukkan prestasi yang membangggakan. Timnas Indonesia berhasil mencapai prestasi tertinggi pada event resmi yaitu juara pada Sea-Games 1991 setelahnya belum sekalipun timnas mencapai prestasi pada event resmi. Tim nasional sepakbola Indonesia yang bertanding pada Sea-Games Singapura 2015 bahkan mengalami kekalahan dengan skor memalukan yaitu dikalahkan thailand 5-0 dibabak semi-final dan kalah 5-0 dari Vietnam pada perebutan medali perunggu atau peringkat ke-3.

Bompa (2015) menyatakan untuk mencapai prestasi optimal seorang atlet harus melakukan beberapa persiapan yaitu fisik, teknik, taktik dan psikologis. Latihan dalam olahraga adalah sesuatu yang saling berhubungan satu sama lainnya tetapi faktor fisik menjadi dasar dari pengembangan faktor-faktor lainnya. Faktor teknik dan taktik harus dipersiapkan setelah fisik dan penentu akhir adalah kesiapan psikologis untuk menjadi juara atau berprestasi optimal. Kondisi fisik menurut Bompa (2015) harus dipersiapkan dalam latihan. Periodesasi latihan fisik diletakkan pada awal latihan dimana kondisi fisik umum dilaksanakan 2-3 bulan dan kondisi fisik khusus cabang olahraga dilaksanakan 2-3 sebelum masa kompetisi. Latihan kondisi fisik pada masa kompetisi diarahkan hanya untuk penyempurnaan atau menjaga kondisi yang telah dicapai pada masa persiapan.

Karakteristik permainan sepakbola mengharuskan setiap pemain mampu berlari pelan (jogging), berlari cepat (sprint), menendang, merebut bola, menyudul dan semua aktifitas fisik tersebut harus mampu dilakukan selama 2 x 45 menit atau 90 menit jika permainan sepakbola untuk orang dewasa, 2 x 40 menit atau 80 menit untuk junior, dan 2 x 20 menit untuk pemain usia dibawah 12 tahun. Berdasarkan data yang diperoleh melalui beberapa penelitian (Reily: 2003) menyatakan bahwa jarak tempuh yang dicapai seorang pemain sepakbola ketika bertanding menempuh jarak 7000-12.000 m.

Pemain sepakbola selain melakukan aktifitas berlari dalam waktu yang lama juga dituntut mampu menendang bola dengan keras, menggiring bola dengan lincah dan cepat, memiliki keseimbangan yang baik ketika melakukan body charge (bertabrakan dengan lawan), koordinasi yang baik untuk mengantisipasi pergerakan lawan dan bola yang arahnya selalu berubah-ubah. Kondisi fisik yang dibutuhkan oleh pemain sepakbola relatif kompleks hampir semua komponen dibutuhkan ketika bermain. FIFA sebagai organisasi yang bertangung jawab terhadap pengembangan sepabola dalam situsnya tahun 2004 menyebarkan sebuah data tentang karakteristik pemain sepakbola elite. Karakteristik permainan sepakbola modern teryata mampu dilakukan dengan karakteristik yang dimiliki oleh tim sepakbola dengan pemain-pemain yang memiliki kemampuan teknik, taktik, mental, fisik seperti dapat dilihat pada tabel 1 dibawah ini: 
MEDIKORA, Vol. 19 No. 1 April 2020 - 35

Sulistiyono

Tabel 1. Karakter Pemain Sepakbola Elite Menurut FIFA

\begin{tabular}{|l|c|}
\hline Tinggi Badan & $181 \mathrm{~cm}$ \\
\hline Berat Badan & $74 \mathrm{~kg}$ \\
\hline VO2 Mak & $60-65 \mathrm{cc}$ \\
\hline Kecepatan Sprint $10 \mathrm{~m}$ & $1 " 78$ \\
\hline Kecepatan Sprint $20 \mathrm{~m}$ & $2 " 89$ \\
\hline Kecepatan Sprint $60 \mathrm{~m}$ & $7 " 43$ \\
\hline Melompat Ke atas (Vertical Jump) & $63 \mathrm{~cm}$ \\
\hline & \\
\hline Cepat dalam bergerak dan berlari \\
\hline Dinamis \\
\hline Keterampilan Teknik Tinggi \\
\hline Daya Ledak Otot \\
\hline Kemampuan untuk pulih lebih cepat \\
\hline Pemahaman terhadap Taktik \\
\hline Kekuatan Mental dan Kontrol diri \\
\hline
\end{tabular}

Sumber: fifa.com

Kondisi fisik seorang pemain sepakbola teryata memiliki peran yang penting jika memperhatikan hasil penelitian tersebut. Data diatas lebih khususnya menyatakan komponen daya tahan jantung paru adalah modal utama untuk sebuah tim sepakbola agar berprestasi. Kondisi fisik merupakan faktor penting yang harus dipersiapkan oleh pelatih sepakbola jika tim yang dipimpinnnya ingin prestasi optimal (menjadi juara) dalam sebuah kompetisi. Bompa (2015) menyatakan kondisi fisik merupakan kemampuan dasar yang harus dibangun dan dikembangkan pada atlet atau olahragawan termasuk pada cabang sepakbola. Kondisi fisik adalah komponen utama yang harus dibagun dengan kokoh agar faktor teknik dan taktik dapat dilakukan sesuai dengan kebutuhan. Atlet atau tim sepakbola yang tidak memiliki kemampuan kondisi fisik yang baik tidak perlu berharap pada target atau sasaran untuk menjadi juara.

Kondisi fisik pemain sepakbola tumbuh dan berkembang secara progresif sejak seseorang memulai latihan dari usia muda sampai usia dewasa. Sekolah sepakbola merupakan organisasi atau lembaga yang melakukan pembinaan sepakbola mulai usia 7-15 tahun. Sekolah sepakbola yang bertugas memberikan kemampuan dasar yang sangat penting, termasuk pembinaan kondisi fisik, jika hal ini tidak dilakukan maka sampai kapanpun prestasi yang menjadi tujuan tidak akan tercapai. Berdasarkan uraian diatas peneliti berkeinginan untuk mengetahui kondisi fisik khususnya komponen kecepatan, daya tahan, kelincahan, dan daya ledak siswa sekolah sepakbola (SSB) kelompok umur 15 tahun tingkat elit dan non-elite di Provinsi Daerah Istimewa Yogyakarta.

\section{METODE}

Penelitian ini adalah peneilitian survey terhadap komponen kondisi fisik utama pada siswa sekolah sepakbola kelompok umur 15 tahun tingkat elit dan non-elit di Provinsi Daerah Istimewa Yogyakarta. Jumlah sampel penelitian ini adalah 30 siswa kelompok elit dan 30 siswa kelompok non-elit. Kriteria sampel kelompok elit adalah siswa SSB terbaik di wilayah Provinsi DIY yang dipilih peneliti dengan pertimbangan siswa pemain utama di SSB, pernah menjuarai kompetisi antar SSB tingkat Provinsi sedangkan kriteria sampel kelompok non-elit adalah siswa SSB di wilayah Provinsi DIY yang dipilih peneliti dengan pertimbangan siswa pemain penggnati di SSB dan belum pernah menjadi juara pada kompetisi antar SSB tingkat Provinsi. Instrumen yang digunakan adalah tes lari cepat $50 \mathrm{~m}$, tes vertical jump, tes lari $1000 \mathrm{~m}$, dan tes lari bolak-balik (shuttle run). 


\section{HASIL DAN PEMBAHASAN}

Pengukuran terhadap komponen kecepatan, daya tahan, kelincahan, dan daya ledak siswa sekolah sepakbola (SSB) kelompok umur 15 tahun tingkat elit dan non elit di Provinsi Daerah Istimewa Yogyakarta diperoleh hasil sebagai berikut:

Tabel 2. Profil Kondisi Fisik Komponen Kecepatan, Daya Tahan, Kelincahan, Dan Daya Ledak Siswa Sekolah Sepakbola (SSB) Kelompok Umur 15 Tahun Tingkat Elit di Provinsi Daerah Istimewa Yogyakarta

\begin{tabular}{|c|c|c|c|c|}
\hline Komponen Fisik & Rata-Rata & Tertinggi & Terendah & Satuan \\
\hline Tinggi Badan & 161,20 & 173 & 152 & $\mathrm{Cm}$ \\
\hline Berat Badan & 53,50 & 57 & 51 & $\mathrm{Kg}$ \\
\hline Daya Tahan & 3,99 & 3,52 & 4,48 & Menit \\
\hline Kecepatan & 6,91 & 6,24 & 7,43 & Detik \\
\hline Kelincahan & 18,33 & 17,10 & 19,40 & Detik \\
\hline Daya Ledak Otot Tungkai & 52,80 & 63 & 34 & $\mathrm{Cm}$ \\
\hline
\end{tabular}

Tabel 3. Profil Kondisi Fisik Komponen Kecepatan, Daya Tahan, Kelincahan, Dan Daya Ledak Siswa Sekolah Sepakbola (SSB) Kelompok Umur 15 Tahun Tingkat Non Elit di Provinsi Daerah Istimewa Yogyakarta

\begin{tabular}{|c|c|c|c|c|}
\hline Komponen Fisik & Rata-Rata & Tertinggi & Terendah & Satuan \\
\hline Tinggi Badan & 151,2 & 166 & 136 & $\mathrm{Cm}$ \\
\hline Berat Badan & 38,5 & 48 & 35 & $\mathrm{Kg}$ \\
\hline Daya Tahan & 5,22 & 4,16 & 8,83 & Menit \\
\hline Kecepatan & 8,28 & 7,13 & 9,57 & Detik \\
\hline Kelincahan & 19,46 & 18,3 & 21 & Detik \\
\hline Daya ledak otot Tungkai & 48 & 60 & 36 & $\mathrm{Cm}$ \\
\hline
\end{tabular}

Tujuan penelitian ini adalah ingin mengetahui profil kondisi fisik siswa SSB kelompok umur 15 tahun antara kelompok elit dan non-elit. Hasil penelitian ini dapat digunakan sebagai pedoman para pelatih SSB di wilayah provinsi DIY yang berkeinginan siswanya berprestasi optimal. Perbedaan antara kelompok elit dan non-elit dapat dibaca selengkapnya pada tabel 4 dibawah ini: 
Tabel 4. Perbandingan Profil Kondisi Fisik Komponen Kecepatan, Daya Tahan, Kelincahan, Dan Daya Ledak Siswa Sekolah Sepakbola (SSB) Kelompok Umur 15 Tahun Tingkat Elit dan Non Elit di Provinsi Daerah Istimewa Yogyakarta

\begin{tabular}{|c|c|c|c|}
\hline \multirow{2}{*}{ Komponen Fisik } & Kelompok Elit & $\begin{array}{c}\text { Kelompok } \\
\text { Non-Elit }\end{array}$ & \multirow{2}{*}{ Satuan } \\
\cline { 2 - 3 } & Rata-Rata & Rata-Rata & \\
\hline Tinggi Badan & 161,20 & 151,2 & $\mathrm{Cm}$ \\
\hline Berat Badan & 53,50 & 38,5 & $\mathrm{Kg}$ \\
\hline Daya Tahan & 3,99 & 5,22 & Menit \\
\hline Kecepatan & 6,91 & 8,28 & Detik \\
\hline Kelincahan & 18,33 & 19,46 & Detik \\
\hline $\begin{array}{c}\text { Daya Ledak } \\
\text { Otot Tungkai }\end{array}$ & 52,80 & 48 & $\mathrm{Cm}$ \\
\hline
\end{tabular}

Komponen fisik memiliki hubungan atau pengaruh yang signifikan terhadap penampilan atau prestasi atlet. Hasil penelitian Ostojic (2002) menyatakan hubungan yang signifikan antara kebugaran aerobik, dan an aerobic power terhadap penampilan pemain sepakbola elit. Komponen daya tahan, kecepatan, kelincahan, dan daya ledak otot tungkai antara kelompok elit dan non-elit memiliki perbedaan yang signifikan. Hasil penelitian ini sesuai dengan teori bahwa untuk berprestasi optimal kondisi fisik harus dipersiapkan dan dimiliki oleh pemain sepakbola. Komponen fisik yang utama yaitu daya tahan, kecepatan, dan kekuatan dalam penelitian ini diwakili oleh daya tahan aerobik dengan tes lari $1000 \mathrm{~m}$, kecepatan dengan tes lari $30 \mathrm{~m}$, dan kelincahan dengan tes shuttle run, kekuatan diwakili dengan daya ledak otot tungkai dengan tes vertical jump.

Daya tahan aerobik yang baik mendukung tim sepakbola untuk mampu bermain dengan pola bermain yang cepat (Bangsbo,1991). Aktifitas permainan sepakbola membutuhkan daya tahan aerobik yang tinggi (baik) hasil penelitian yang dilakukan oleh Abdul Aziz Rashid dkk pada tahun 2002-2004 pada para pemain klub di Liga Singapura membuktikan bahwa peringkat klasemen akhir memiliki hubungan dengan kemampuan daya tahan aerobik. Selengkapnya bisa dibaca pada tabel 5 dan 6 . 
MEDIKORA, Vol. 19 No. 1 April 2020 - 38

Sulistiyono

Tabel 5. Hasil Pengukuran Kondisi Fisik (Daya Tahan Aerobik yang Diukur dengan Tes Multistage Shutle Run) Hubungannya dengan Rangking Klub di Liga Sepakbola Singapura pada Masa Kompetisi 2002

\begin{tabular}{|c|c|c|c|c|c|c|c|c|c|c|c|c|}
\hline \multirow[t]{2}{*}{ Club } & \multirow{2}{*}{$\begin{array}{c}\text { Number } \\
\text { of } \\
\text { player }\end{array}$} & \multirow{2}{*}{ MST } & \multicolumn{4}{|c|}{$\begin{array}{l}\text { Number of } \\
\text { matches }\end{array}$} & & \multirow{2}{*}{$\begin{array}{l}\text { Goals } \\
\text { again d }\end{array}$} & \multirow{2}{*}{$\begin{array}{r}\text { Goals } \mathrm{p} \\
\text { difference } \mathrm{o}\end{array}$} & percentage & \multirow{2}{*}{ Total } & \multirow[t]{2}{*}{ Ranking } \\
\hline & & & Won I & Draw & Lost & & & & & of matches & & \\
\hline $\mathrm{L}$ & 10 & $121+13$ & 21 & 2 & 5 & 5 & 90 & 30 & 60 & 75 & 65 & $1 \mathrm{st}$ \\
\hline I & 15 & $122+16$ & 20 & 0 & $\varepsilon$ & 8 & 83 & 36 & 47 & 69 & 60 & 2nd \\
\hline $\mathrm{O}$ & 12 & $119 \pm 11$ & 17 & 3 & $\varepsilon$ & 8 & 74 & 44 & 30 & 65 & 54 & 3rd \\
\hline $\mathrm{D}$ & 13 & $120 \pm 11$ & 17 & 2 & S & 9 & 60 & 43 & 17 & 56. & 53 & 4 th \\
\hline $\mathrm{C}$ & 11 & $122+\underline{3}$ & 13 & 8 & 7 & 7 & 55 & 42 & 13 & 46. & 47 & 5 th \\
\hline E & 14 & $115+12$ & 11 & 9 & $\varepsilon$ & 8 & 67 & 49 & 18 & 42. & 43 & 7 th \\
\hline A & 15 & $129+16$ & 11 & 7 & & 10 & 44 & 30 & 14 & 33 & 37 & 6th \\
\hline B & 10 & $111 \pm 11$ & 7 & 2 & & 19 & 56 & 73 & -17 & 21. & 23 & 8th \\
\hline $\mathrm{N}$ & 17 & $119 \underline{+3}$ & 5 & 5 & & 18 & 40 & 60 & -40 & 16. & 20 & 9th \\
\hline M & 18 & $110 \underline{+4}$ & 3 & 5 & & 20 & 30 & 67 & -37 & 13. & 14 & 10th \\
\hline
\end{tabular}

Table 6. Hasil Pengukuran Kondisi Fisik (Daya Tahan Aerobik yang Diukur dengan Tes Multistage Shutle Run) Hubungannya dengan Rangking Klub di Liga Sepakbola Singapura pada Masa Kompetisi 2003

\begin{tabular}{|c|c|c|c|c|c|c|c|c|c|c|c|}
\hline \multirow[t]{2}{*}{ Club } & \multirow{2}{*}{$\begin{array}{l}\text { Number } \\
\text { of player }\end{array}$} & \multirow[t]{2}{*}{ MST } & \multicolumn{3}{|c|}{$\begin{array}{l}\text { Number of } \\
\text { matches }\end{array}$} & \multirow{2}{*}{$\begin{array}{c}\text { Goals } \\
\text { for } \\
\end{array}$} & \multirow{2}{*}{$\begin{array}{l}\text { Goals } \\
\text { again }\end{array}$} & \multirow{2}{*}{$\begin{array}{c}\text { Goals } \\
\text { difference }\end{array}$} & \multirow{2}{*}{$\begin{array}{l}\text { percentage } \\
\text { of matches }\end{array}$} & \multirow{2}{*}{$\begin{array}{l}\text { Total } \\
\text { Point }\end{array}$} & \multirow[t]{2}{*}{ Ranking } \\
\hline & & & Won & Draw & Lost & & & & & & \\
\hline $\mathrm{D}$ & 13 & $116 \underline{+1}$ & 20 & 3 & 4 & 76 & 29 & 47 & 74.1 & 63 & $1 \mathrm{st}$ \\
\hline B & 15 & $120+1$ & 17 & 2 & 8 & 76 & 43 & 33 & 63 & 53 & 2nd \\
\hline $\mathrm{N}$ & 14 & $109 \pm 1$ & 14 & 5 & 8 & 74 & 52 & 22 & 51.9 & 47 & $3 \mathrm{rd}$ \\
\hline A & 14 & $117 \underline{ \pm}$ & 14 & 3 & 10 & 45 & 48 & -3 & 51.9 & 45 & 4th \\
\hline $\mathrm{O}$ & 16 & $132 \pm 4$ & 12 & 8 & 7 & 50 & 42 & 8 & 44.4 & 44 & 5 th \\
\hline $\mathrm{E}$ & 11 & $124 \pm 1$ & 12 & 4 & 11 & 48 & 49 & -1 & 44.4 & 37 & 7th \\
\hline $\mathrm{C}$ & 14 & $126 \pm 9$ & 10 & 7 & 10 & 43 & 43 & 0 & 37 & 40 & 6 th \\
\hline $\mathrm{K}$ & 14 & $114 \pm 1$ & 6 & 2 & 19 & 36 & 73 & -37 & 22.2 & 20 & 8th \\
\hline M & 13 & $120 \pm 7$ & 4 & 5 & 18 & 36 & 62 & -26 & 14.8 & 17 & 9 th \\
\hline $\mathrm{L}$ & 14 & $12 \underline{0+1}$ & 4 & 5 & 18 & 29 & 72 & -43 & 14.8 & 17 & 10th \\
\hline
\end{tabular}


Berdasarkan data penelitian Abdul Rashid dan penelitian ini maka dapat dinyatakan komponen daya tahan jantung paru adalah modal utama untuk sebuah tim sepakbola agar berprestasi. Hasil penelitian yang kedua adalah komponen daya ledak otot tungkai kelompok elit memiliki hasil rata-rata 52,80 dan kelompok non-elite $48 \mathrm{~cm}$. Daya ledak otot tungkai memiliki peran penting dalam mendukung teknik menendang bola. Tendangan yang bertujuan untuk mencetak gol (shooting) harus dilakukan dengan keras (bola hasil tendangan memiliki kecepatan tinggi) agar tidak mudah diantisipasi penjaga gawang. Tendangan yang keras jika dinalisis memiliki ketetapan sebagai berikut:

$$
\mathrm{V} \text { bola }=1.2 \times \mathrm{V} \mathrm{kaki}+2,72 \text { (Adrian Lee, 2001) }
$$

Dengan ketetapan tersebut maka daya ledak otot tungkai yang dipengaruhi oleh kinerja kekuatan dan kecepatan otot dalam menahan beban, maka sangat berperan penting dalam kinerja sebagai pemain sepakbola.

\section{SIMPULAN}

Hasil penelitian menunjukkan perbedaan yang signifikan antara komponen kondisi fisik daya tahan aerobik, kecepatan, kelincahan, dan daya ledak otot tungkai kelompok elit dan nonelit pada siswa SSB Kelompok Umur 15 tahun di Provinsi DIY. Kelompok elit memiliki kemampuan yang rata-rata lebih baik dibanding non-elit terutama pada komponen daya tahan yang sangat mendukung seorang pemain sepakbola untuk tampil konsisten selama delapan puluh menit.

Hasil penelitian ini sangat bermanfaat untuk pelatih atau pengurus sekolah sepakbola dimana dengan mengacu pada penelitian ini maka proses latihan harus diarahkan untuk mencapai target kondisi fisik seperti yang dihasilkan pada penelitian ini. Komponen kondisi fisik yang lainnya bukan berarti tidak penting tetapi komponen fisik yang dominan pada suatu cabang olahraga harus menjadi perhatian khusus agar prestasi yang menjadi harapan pada proses pembinaan olahraga dapat tercapai.

\section{DAFTAR PUSTAKA}

Abdul Rashid Aziz, Michael J. Newton, Taisuke Kinugasa and Teh Kong Chuan. 2007. Relationship between Aerobic Fitness and League Positional Ranking of Clubs in a Professional Soccer League over Three Competitive Seasons. Journal Footbal Science Volume 4-9-18-2007. www.jfss.net

Bompa. O. Tudor and Carera, M. 2015. Conditioning Young Athlete. Human Kinetic: USA.

Bangsbo, J., Norregaarg, L. and Thorso, F. (1991) Activity profile of competition soccer. Canadian Journal of Sport Sciences 16, 110-116.

Fifa.com. Characateris elite athlete

Ostojic, S. (2002) Antropometric, physiological and biochemical characteristics of elite Yugoslav soccer players. Doctoral thesis, Medical faculty, University of Belgrade, Belgrade. 1-182. (In Serbian: English abstract).

Reily, T and Williams, Mark, A. 2003. Science and Soccer. Second Edition. Routledge: New York: USA. 